\title{
Compliance with the Australian 24-hour movement guidelines for the early years: associations with weight status
}

Rute Santos ${ }^{1,2^{*}}$, Zhiguang Zhang ${ }^{1}$, João R. Pereira ${ }^{1,3}$, Eduarda Sousa-Sá ${ }^{1}$, Dylan P. Cliff ${ }^{1,4}$ and Anthony D. Okely ${ }^{1}$

\begin{abstract}
Background: For effective public health and surveillance it is important to document the proportion of young children who meet the new Australian Integrated $24 \mathrm{~h}$ Movement Guidelines for the Early Years and how these associate with health outcomes. We aimed to (i) assess compliance with the new Integrated $24 \mathrm{~h}$ Movement Guidelines for the Early Years in a sample of Australian toddlers; and (ii) ascertain whether compliance with the guidelines associates with weight status.

Methods: The sample comprised 202 toddlers (104 girls) aged $19.74 \pm 4.07$ months from the GET UP! Study. Participants wore accelerometers (Actigraph GT3X+) for 24 h over 7 consecutive days to assess physical activity, sedentary time and sleep. Parents reported participants' screen time. Weight and height were measured and body mass index (BMI) z-scores by age and sex were calculated. Analysis of Covariance (ANCOVA) was performed to test differences in BMI z-scores between participants complying with (i) none or any individual guideline, (ii) any combination of meeting two guidelines, and (iii) those who met all three guidelines, adjusting for child age, gender and socioeconomic status.
\end{abstract}

Results: Only $8.9 \%$ of the sample met the overall $24 \mathrm{~h}$ movement guidelines. Most of the sample met the physical activity (96.5\%) and sleep (79.7\%) guidelines but only $11.4 \%$ met the sedentary behavior guideline. Average BMI Z-scores did not significantly differ between children who complied with none or any individual guideline, any combination of meeting two guidelines, and those who met all three guidelines $(p>0.05)$. Although the lack of significant differences, participants who accomplished any combination of two guidelines or all three guidelines appear to have had a lower BMI Z-score than those complying with one of the guidelines or none.

Conclusions: Just under 9\% of our sample met the overall Australian $24 \mathrm{~h}$ Movement Guidelines for the Early Years. BMI was not associated with the accomplishment of any of the 24-h Movement Guidelines. Strategies to promote adherence to the 24-h movement guidelines in toddlers, particularly for screen time, are necessary, as promoting health-related behaviors in early childhood has the potential to provide children a strong foundation for lifelong physical and mental health.

Keywords: Adiposity, Body mass index, Recommendations, Physical activity, Sedentary behavior, Childhood, Screen time, Sleep

\footnotetext{
*Correspondence: rutes@uow.edu.au

${ }^{1}$ Early Start, Faculty of Social Sciences, University of Wollongong,

Wollongong, NSW 2522, Australia

${ }^{2}$ Research Centre in Physical Activity, Health and Leisure, Faculty of Sport,

University of Porto, Porto, Portugal

Full list of author information is available at the end of the article
} 


\section{Background}

Overweight and obesity during childhood are major public health concerns. Globally it is estimated that $6.7 \%$ of children under the age of 5 are overweight or obese and it is expected that this prevalence will reach $9.1 \%$ by 2020 [1]. In Australia, the prevalence of overweight and obesity in pediatric ages has increased substantially in the last two decades, particularly among those from low socio-economic backgrounds [2, 3]. Although the prevalence has leveled off somewhat over the past decade [2, 3], there are still 1 in 5 Australian children aged 2 to 4 years who are overweight or obese [4]. These figures are particularly disturbing given the plethora of short term and long-term adverse health consequences associated with childhood overweight and obesity $[5,6]$.

From a movement perspective, sleep, sedentary behavior and physical activity represent a continuous range of movement (from none/low to high) with a daily time allocation of these behaviors representing portions of a 24-h period [7, 8]. The new evidence-based Canadian and Australian Integrated 24-h Movement Guidelines for the Early Years acknowledge this movement continuum over the 24-h period and provide guidance for each of the behaviors that compose the whole day: sleep, sedentary behavior and physical activity [9]. For effective public health and surveillance, it is important to document the proportion of young children meeting each of these guidelines as well their combination and how these associate with health outcomes.

Studies have shown that time spent in each of these behaviors generally associate with early childhood adiposity, despite some mixed findings [10-16]. However, there are only a few studies with toddlers looking at the relationship between each of movement behaviors and their combination with adiposity [13-16].

In this context, the aims of this study were to (i) assess compliance with the new Integrated 24-h Movement Guidelines for the Early Years in a sample of Australian toddlers; and (ii) ascertain whether compliance with the guidelines associates with weight status.

\section{Methods}

\section{Study design and sampling}

This paper reports on a cross-sectional analysis of the baseline data from the Get Up! Study, a cluster randomized controlled trial aimed to evaluate the effects of reduced sitting on toddlers' cognitive development. Detailed description of sampling, rationale and data collection procedures of this study are described elsewhere [17]. Briefly, baseline data were collected in 2016 in 335 apparently healthy toddlers (155 girls), i.e. without any medication or medical diagnosis of physical or mental impairment, aged $19.8 \pm 4.08$ months; of these, 284 had valid accelerometer data and 202 had data on screen time. Therefore, the final sample for this paper comprises 202 toddlers (aged 12 to 28 months).

The Get Up! Study was conducted in accordance with the Helsinki Declaration for Human Studies and approved by the University of Wollongong's Human Research Ethics Committee (HE15/236) and the RCT was registered in the Australian and New Zealand Clinical Trials Registry (ACTRN12616000471482, 11/04/ 2016, retrospectively registered). Informed written consent was obtained from children's parents or guardians.

\section{Measures \\ Physical activity, sedentary time and sleep}

Physical activity, sedentary time and sleep over a usual week were measured with Actigraph GT3X+ accelerometers. These accelerometers have established validity and utility in toddlers $[18,19]$. Participants were asked to wear the accelerometer, attached tightly on the right hip, for $24 \mathrm{~h}$ /day over 7 consecutive days and parents and educators were asked to register, in an activity monitor log, the times that the accelerometer was removed from the child, as well as the naps and night sleep hours. Data were collected using a sampling rate of $30 \mathrm{~Hz}$ and then reintegrated into $15 \mathrm{~s}$ epoch for analysis.

Considering the accelerometers logs, data files from individual participants were manually and visually screened to detect naps, nighttime sleep periods and non-wear time. Participants had to have at least 1 day (i.e. one period of 24-h) with accelerometer data to be included in the analyses. After screening was completed, the raw activity 'counts' were processed for determining the time spent in sedentary behaviors and different physical activity intensities.

Accelerometer cut-points for toddlers were used as follows: sedentary time $<25$ counts/15 s; 25-420 counts/ $15 \mathrm{~s}$; moderate to vigorous physical activity (MVPA) $>420$ counts/15 s [18]. A bout of sedentary time was defined as a period of time that was maintained completely at an intensity level of less than $<25$ counts/15 s, for one hour or longer. Accelerometer data were analyzed using an automated data reduction program (ActiLife Software, version 6.12.1 for Windows).

\section{Body mass index}

Body height was measured to the nearest $0.1 \mathrm{~cm}$ in bare or stocking feet with the child standing upright against a portable stadiometer (Seca 254 Hamburg, Germany). Body weight was measured to the nearest $0.10 \mathrm{~kg}$, with the child lightly dressed (and without diapers) using a portable electronic weight scale (Seca 254 Hamburg, Germany). Body mass index (BMI) was calculated as weight $(\mathrm{kg}) /$ height $(\mathrm{m})^{2}$. BMI Z-scores by age and sex were calculated. Participants were classified as underweight, 
normal weight, overweight or obese according to the World Health Organization age and sex specific criteria [20].

\section{Screen time}

Parents were asked to report the child's screen time by answering the following questions: "For how long does your child use screen entertainment on a typical weekday?" and "For how long does your child use screen entertainment on a typical weekend day?" Time reported in both questions was summed as follows: (screen time weekdays * $5+$ screen time weekend days $* 2$ ) / 7 = average screen time per day.

\section{Socio-economic status}

Family socio-economic status was assessed using the family postcode address as a proxy-measure of the child socio-economic status, according to the Australian Socio-Economic Indexes for Areas 2011 (SEIFA-Index of Relative Socio-Economic Disadvantage) [21].

\section{Operational definitions of the integrated $24 \mathrm{~h}$ movement guidelines \\ Physical activity}

Participants were classified as meeting the physical activity guideline if they averaged at least 180 min per day of physical activity of any intensity (i.e., light, moderate or vigorous intensity physical activity), including at least 1 min of MVPA, as the guidelines for physical activity include "some energetic play" within these $180 \mathrm{~min}$ of physical activity.

\section{Sedentary behavior}

Participants were classified as meeting the sedentary behavior guideline if they had concurrently (i) no bouts of sedentary time lasting one or more hours; and (ii) no screen time (for those aged $\leq 24$ months) or less than $1 \mathrm{~h}$ /day of screen time (for those aged $>24$ months).

\section{Sleep}

Participants were classified as meeting the sleep guideline if their average sleep duration was between 11 and $14 \mathrm{~h}$ per $24-\mathrm{h}$, including nap(s) and night time sleep.

\section{Statistics}

Descriptive characteristics are presented as means and standard deviations (SD) for continuous variables and as percentages for categorical variables. Two-tailed Student t-tests or Mann-Whitney U Test and Chi-square tests were performed to assess gender differences for continuous and categorical variables, respectively.

For descriptive purposes only, consistency of bedtime and wake up time was calculated as the intra-subject standard deviation of the average bedtime and wake up time of each participants that had at least 2 days of accelerometer data $(n=173)$.

Analysis of Covariance (ANCOVA) was performed to test differences in BMI z-scores between participants complying with (i) none or any individual guideline, (ii) any combination of meeting two guidelines, and (iii) those who met all three guidelines, adjusting for child age, gender and socioeconomic status.

A 0.05 level of statistical significance was considered. Data analysis was performed using IBM SPSS ${ }^{\oplus}$, version 24.0 (SPSS Inc., Chicago, IL, USA).

\section{Results}

Descriptive characteristics of the participants are presented in Table 1 . Boys had on average less sedentary time than girls $(p<0.05)$. None of the participants had sedentary bouts of $1 \mathrm{~h}$ or more. The percentage of overweight and obese participants was 22.8 and 4\%, respectively. Regarding accelerometer wear time, $14.4 \%$ of participants had 1 day (i.e. one 24-h period) of accelerometer data, $4 \%$ had 2 days and $81.6 \%$ had 3 or more days of accelerometer data; and children were monitored on average for $5.14 \pm 2.27$ days. Average accelerometer wear time was $1297.4 \pm 93.0 \mathrm{~min}$ per day.

Figure 1 shows the proportion (\%) of toddlers meeting no guidelines, one guideline and combinations of the three guidelines. Most of the sample (96.5\%) met the physical activity guideline, but only $11.4 \%$ met the sedentary behavior guideline. Only $2.5 \%$ of the sample did not meet any of the guidelines, $16.3 \%$ met at least one guideline, $72.3 \%$ met at least two guidelines and $8.9 \%$ of the sample met all three guidelines. Children that met the physical activity guideline had at least $15.5 \mathrm{~min} /$ day of MVPA. The Figure - Additional file 1, shows the proportion (\%) of toddlers meting no guidelines, physical activity, sedentary behavior, sleep guidelines and the combinations of these guidelines, separately for girls and boys. No significant differences were found between genders regarding the proportion of toddlers meeting the guidelines $\left(\mathrm{X}^{2}=0.929, p=0.629\right)$.

As shown in Figs. 2, 3 and 4 and Additional file 2 average BMI Z-scores did not differ between children who met none or single guidelines, any combination of meeting two guidelines, or all three guidelines $(p>0.05)$.

\section{Discussion}

Using 24-h accelerometer data, we found that just under $10 \%$ of toddlers met all three of the current Australian 24 h Movement Guidelines for the Early Years. Nearly the whole sample (96.5\%) met the physical activity guideline and only $11.4 \%$ met the sedentary behavior guideline. Our results are consistent with those reported for Canadian toddlers and Australian and Canadian preschoolers. The reports of Lee et al. [22], Chaput et al. 
Table 1 Participants Characteristics (mean \pm standard deviation)

\begin{tabular}{|c|c|c|c|c|}
\hline & Total Sample $(n=202)$ & Girls $(n=104)$ & Boys $(n=98)$ & $p^{c}$ \\
\hline Age (months) & $19.74 \pm 4.072$ & $19.76 \pm 4.05$ & $19.71 \pm 4.12$ & 0.884 \\
\hline BMI $\left(\mathrm{kg} / \mathrm{m}^{2}\right)$ & $17.95 \pm 1.64$ & $17.78 \pm 1.71$ & $18.14 \pm 1.56$ & 0.427 \\
\hline BMI z-scores & $0.07 \pm 0.93$ & $0.06 \pm 0.98$ & $0.08 \pm 0.89$ & 0.934 \\
\hline Total physical activity (min/day) & $294.97 \pm 59.03$ & $289.98 \pm 57.92$ & $300.27 \pm 60.02$ & 0.109 \\
\hline Light physical activity (min/day) & $237.65 \pm 44.92$ & $235.95 \pm 45.14$ & $239.45 \pm 44.86$ & 0.351 \\
\hline Moderate to vigorous physical activity (min/day) & $57.32 \pm 21.40$ & $54.03 \pm 18.42$ & $60.82 \pm 23.77$ & 0.055 \\
\hline Sedentary time (min/day) & $262.77 \pm 60.16$ & $271.18 \pm 59.97$ & $253.85 \pm 59.37$ & 0.025 \\
\hline Screen time (min/day) & $76.38 \pm 62.81$ & $77.71 \pm 71.98$ & $74.97 \pm 51.66$ & 0.557 \\
\hline Sleep time $(\min / \text { day })^{a}$ & $739.66 \pm 73.96$ & $731.18 \pm 72.25$ & $784.66 \pm 75.05$ & 0.126 \\
\hline $\begin{array}{l}\text { Consistency of bedtime (standard deviation of } \\
\text { average bedtime in min) }\end{array}$ & $44.71 \pm 31.12$ & $42.51 \pm 23.42$ & $47.05 \pm 37.61$ & 0.907 \\
\hline $\begin{array}{l}\text { Consistency of wake up time (standard deviation } \\
\text { of average wake up time in min) })^{b}\end{array}$ & $45.56 \pm 36.42$ & $47.53 \pm 45.8$ & $43.5 \pm 22.71$ & 0.410 \\
\hline Accelerometer wear time (min/day) & $1297.40 \pm 93.00$ & $1292.34 \pm 95.06$ & $1302.78 \pm 90.93$ & 0.355 \\
\hline
\end{tabular}

$B M I$ body mass index

aincluding nap(s) time

banalysis performed on a subsample of 173 toddlers with at least 2 days of accelerometers data

cCompares genders with Two-Tailed T-test (BMI) or Mann Whitney U Test (all other variables

Bold significant difference between boys and girls $(p<0.05)$

[23] and Cliff et al. [24], in this supplement, also show that the majority of young children met the physical activity guideline and that $15 \%$ or less met all three guidelines of the 24-h Movement Guidelines for the Early Years.

As none of the participants had sedentary bouts of $1 \mathrm{~h}$ or more, these $11.4 \%$ that met the sedentary behavior

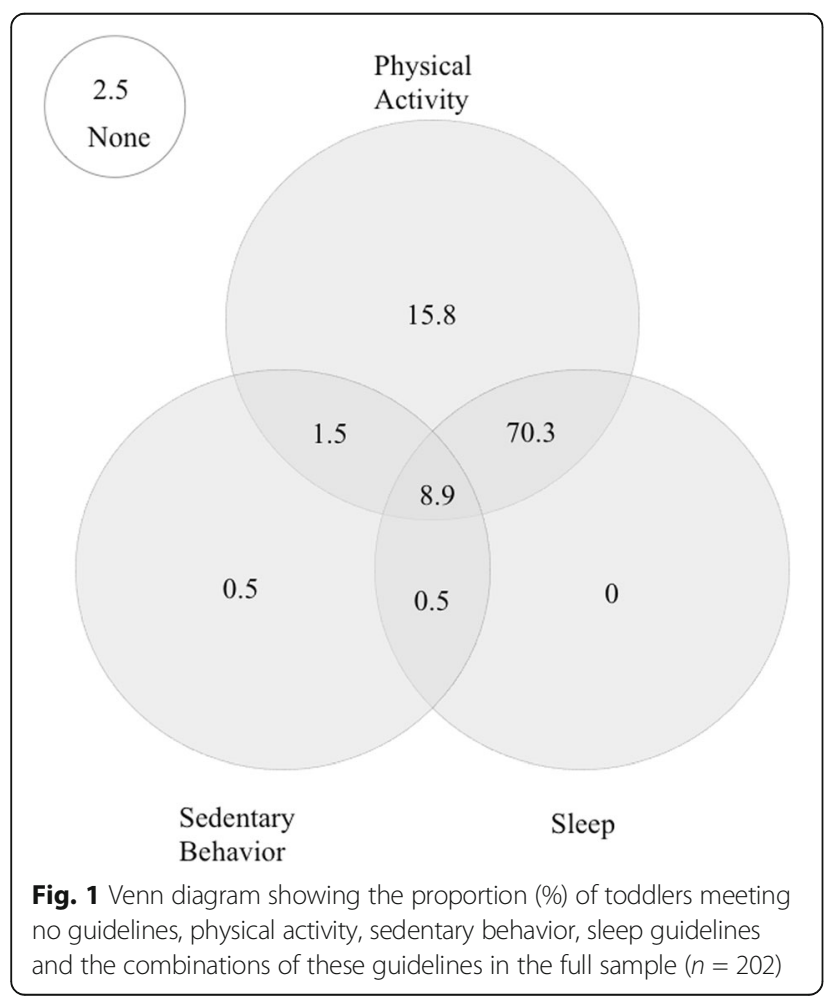

guideline reflects the amount of children meeting the screen time component of the sedentary behavior guideline; which is of concern given the potential long-term health impacts of excessive screen-based sedentary behaviors during the first years of life [16]. In our study, girls spent on average more time in sedentary behaviors than boys, a finding that is consistent with previous studies in older children [25-27] but contradicts others [28-31]. In this respect, it is important to notice that the correlates of sedentary behavior appear to be dependent on the type and context of the behavior, as well as how sedentary behavior is assessed [27-33]. Also, as sedentary behaviors seem to track from early childhood to middle childhood [34] and from childhood to adolescence $[35,36]$ efforts to limit the amount of time spent in sedentary pursuits from an early age are therefore necessary.

The proportion of overweight and obese children in our sample $(26.8 \%)$ is higher than the most recent data for Australian toddlers and pre-schoolers (22.8\%) [4], most likely because our study was conducted with children living in low socio-economic areas. Average BMI Z-scores did not differ significantly between children who complied with none or any individual guideline, any combination of meeting two guidelines, and those who met all three guidelines $(p>0.05)$. Although the differences were not statistically significant, participants who accomplished any combination of two guidelines or all three guidelines appear to have a lower BMI Z-score, than those complying with one of the guidelines or none. These results are in line with the systematic reviews presented in this supplement, where in children 


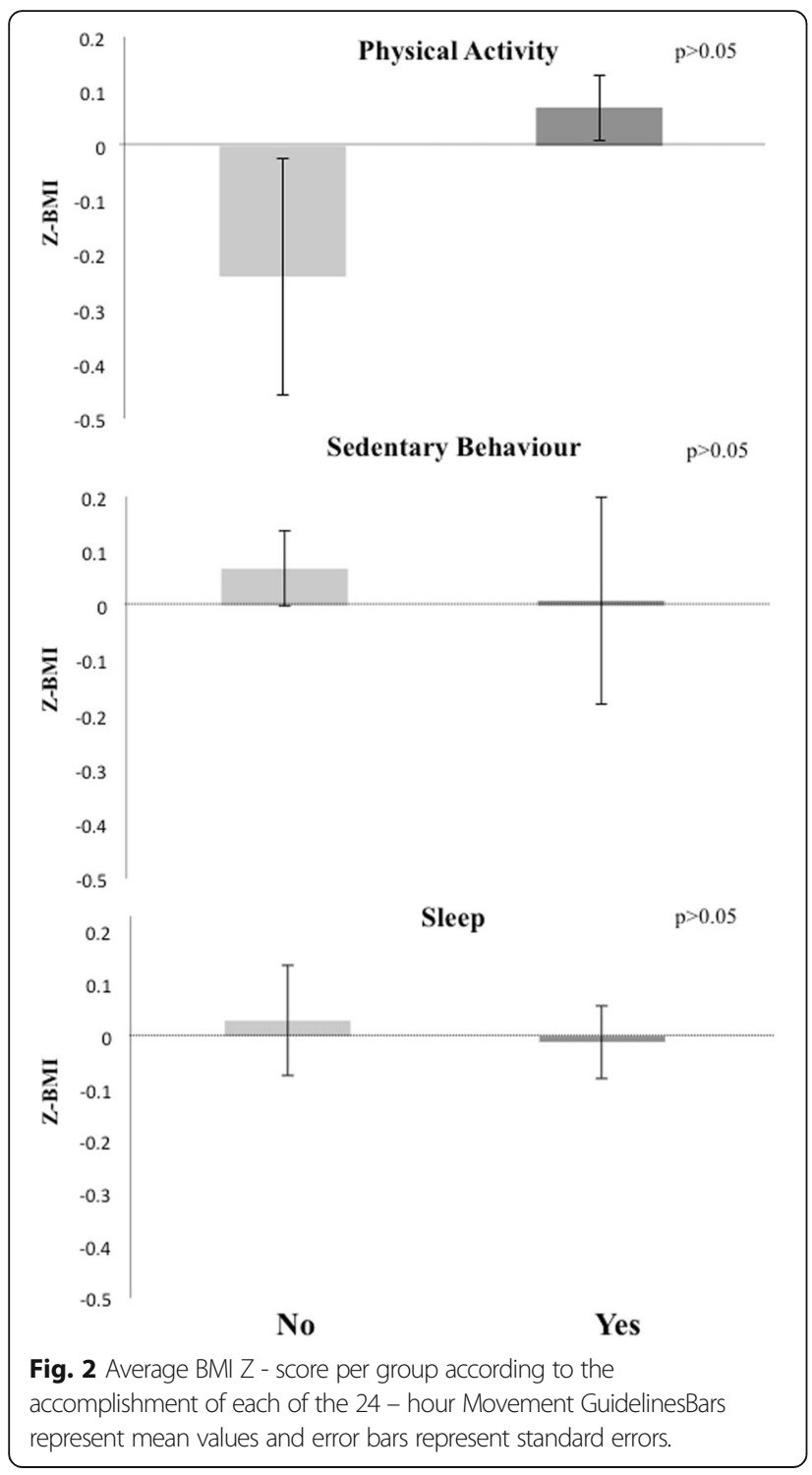

aged 0 to 4 years, the associations between adiposity and sedentary time, screen-based sedentary behaviors, shorter sleep duration and lower levels of physical activity, as well as the combination of these were predominantly unfavorable or null [13-16]. Our results also agree with those presented by Lee et al. [22] and Chaput et al. [23] for Canadian toddlers and preschoolers, in this supplement; but contrast with previous findings in older children and adolescents, where such associations were mainly unfavorable [37-40]. Indeed, it seems less likely to find significant associations between the behaviors that are included in the 24-h movement guidelines and adiposity in samples of apparently healthy toddlers, as the deleterious effects of accumulating low physical activity levels, short sleep, higher sedentary time and sedentary screen-based activities on adiposity are likely to

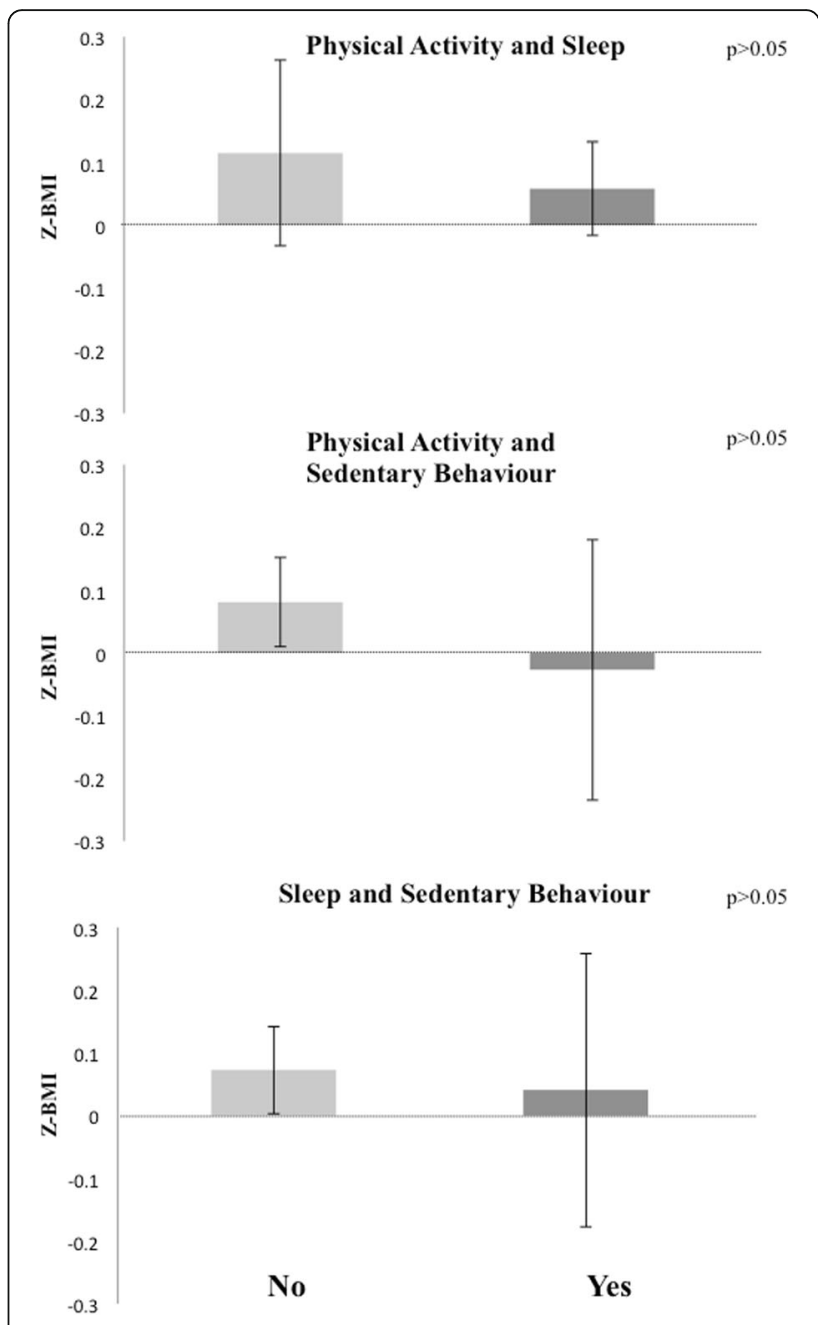

Fig. 3 Average BMI Z - score per group according to the accomplishment of combinations of two 24 - hour Movement Guidelines. Bars represent mean values and error bars represent standard errors

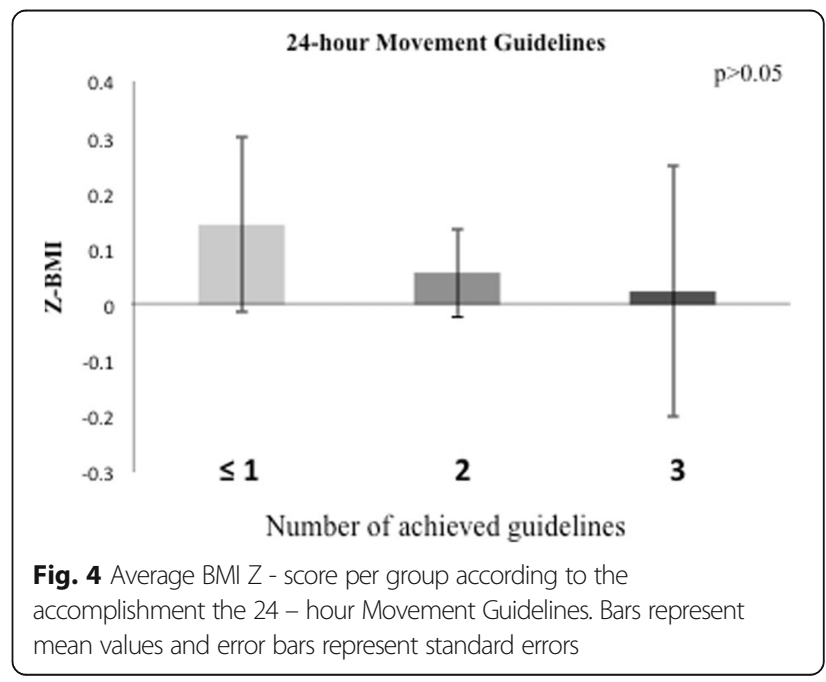


manifest over time, as children get older. Nevertheless, our study is unique in the sense that we measured objectively all movement behaviors over a 24-h period with accelerometers (except screen time) and therefore, direct comparisons with previous studies that used different assessments tools, over different periods of the day, including proxy reports, in toddlers, should be made with caution.

Our study is not without limitations. First, we used accelerometer's cut-points that were developed for slightly older toddlers that those included in our sample (24 months versus 19 months) [18]; and as children's motor development changes rapidly during the first 2 years of life, the use of this cut-points may have potentially introduced some measurement inaccuracy. Second, our inclusion criteria was limited to 1 day with 24-h of accelerometer data, which may not be representative of a child's usual movement behavior; however, the majority of our sample (81.6\%) had at least 3 days of accelerometer wear time and children were monitored on average for 5 days, which is consistent with previous data in older children [41]. Other limitations include the cross-sectional design of our study, which precludes establishing causality and the fact that we did not consider other potential confounders in our analysis, such as dietary intake. Finally, our sample is not nationally representative and therefore our results may not generalize to the Australian population.

As prevalence estimates affect public health policies and interventions, it is paramount that the prevalence rates are measured as accurately as possible. In this sense, the use of 24-h accelerometer data is the greatest strength of this study.

\section{Conclusions}

Using $24 \mathrm{~h}$ accelerometer data, we found that just under $9 \%$ of our sample of toddlers met all three of the current Australian 24-h Movement Guidelines for the Early Years, which was mainly due to the low compliance of the sedentary behavior guidelines (11.4\%) (i.e. screen time component). The large majority of the sample (96.5\%) met the physical activity guideline. BMI was not associated with the accomplishment of the 24-h Movement Guidelines. Further studies with more robust designs and larger samples are necessary to confirm or rule out our findings.

Strategies to promote adherence to the 24-h movement guidelines in toddlers, particularly for screen time, are necessary, as promoting health-related behaviors in early childhood has the potential to provide children a strong foundation for lifelong physical and mental health.

\section{Additional files}

Additional file 1: Mean BMI Z-scores according to level of compliance with the $24 \mathrm{~h}$ Movement Guidelines. (DOCX $17 \mathrm{~kb}$ )

Additional file 2: Venn diagram showing the proportion (\%) of toddlers meeting no guidelines, physical activity, sedentary behavior, sleep guidelines and the combinations of these guidelines for girls $(n=104)$ and boys $(n=98)$. (TIFF $1521 \mathrm{~kb})$

\section{Abbreviations}

BMI: Body Mass Index; MVPA: Moderate to vigorous physical activity; SEIFA: Index of relative socio-economic disadvantage

\section{Acknowledgements}

R Santos has a Discovery Early Career Research Award from the Australian Research Council (DE150101921). DP Cliff has a Discovery Early Career Research Award from the Australian Research Council (DE140101588). Z Zhang has a PhD scholarship from the China Scholarship Council. E. Sousa-Sá and J R Pereira have PhD Scholarships from the University of Wollongong. The authors are grateful to Associate Professor J P Chaput for his helpful comments on the sleep data of this manuscript.

\section{Funding}

This study was supported by the Australian Research Council (DE150101921) and by the University of Wollongong. Publication costs were supported by the University of Wollongong.

\section{Availability of data and materials}

Not applicable

\section{About this supplement}

This article has been published as part of BMC Public Health Volume 17 Supplement 5, 2017: 24-Hour Movement Guidelines for the Early Years: An Integration of Physical Activity, Sedentary Behaviour, and Sleep. The full contents of the supplement are available online at https://bmcpublichealth. biomedcentral.com/articles/supplements/volume-17-supplement-5.

\section{Authors' contributions}

RS and ADO lead the designing the study. DPC provided expert input in the conception of the manuscript. RS and ZZ performed statistical analyses. ZZ, ES, JRP collected data and analysed accelerometer data. All authors participated in the revision of the manuscript and approved the final version.

\section{Ethics approval and consent to participate}

Approval was obtained from the University of Wollongong's Human Research Ethics Committee (HE15/236) and the RCT was registered in the Australian and New Zealand Clinical Trials Registry (ACTRN12616000471482, 11/04/ 2016, retrospectively registered).

\section{Consent for publication}

Informed written consents were obtained from children's parents or guardians.

\section{Competing interests}

All authors declare that they have no competing interests.

\section{Publisher's Note}

Springer Nature remains neutral with regard to jurisdictional claims in published maps and institutional affiliations.

\section{Author details}

${ }^{1}$ Early Start, Faculty of Social Sciences, University of Wollongong, Wollongong, NSW 2522, Australia. ${ }^{2}$ Research Centre in Physical Activity, Health and Leisure, Faculty of Sport, University of Porto, Porto, Portugal. ${ }^{3}$ Research Centre in Sport and Physical Activity, Faculty of Sport Science and Physical Education, University of Coimbra, Coimbra, Portugal. ${ }^{4}$ lllawarra Health and Medical Research Institute, University of Wollongong, Wollongong, Australia. 


\section{Published: 20 November 2017}

\section{References}

1. de Onis M, Blossner M, Borghi E. Global prevalence and trends of overweight and obesity among preschool children. Am J Clin Nutr. 2010;92(5):1257-64.

2. Hardy LL, Mihrshahi S, Gale J, Drayton BA, Bauman A, Mitchell J. 30-year trends in overweight, obesity and waist-to-height ratio by socioeconomic status in Australian children, 1985 to 2015. Int J Obes. 2017:41(1):76-82.

3. O'Dea JA, Dibley MJ. Prevalence of obesity, overweight and thinness in Australian children and adolescents by socioeconomic status and ethnic/ cultural group in 2006 and 2012. Int J Public Health. 2014;59(5):819-28.

4. ABS. Australian Bureau of Statistics. National Health Survey: First Results, 2011-12. http://www.abs.gov.au/ausstats/abs@.nsf/Lookup/by Subject/4338. 0 2011-13 Main Features Children\%27s risk factors 10010 Accessed 5 June 2017. 2013.

5. Pulgaron ER. Childhood obesity: a review of increased risk for physical and psychological comorbidities. Clin Ther. 2013;35(1):A18-32.

6. Sanders RH, Han A, Baker JS, Cobley S. Childhood obesity and its physical and psychological co-morbidities: a systematic review of Australian children and adolescents. Eur J Pediatr. 2015:174(6):715-46.

7. Carson V, Tremblay MS, Chaput J-P, Chastin SF. Associations between sleep duration, sedentary time, physical activity, and health indicators among Canadian children and youth using compositional analyses 1. Appl Physiol Nutr Metab. 2016:41(6):S294-302.

8. Chastin SF, Palarea-Albaladejo J, Dontje ML, Skelton DA. Combined effects of time spent in physical activity, sedentary behaviors and sleep on obesity and cardio-metabolic health markers: a novel compositional data analysis approach. PLoS One. 2015;10(10):e0139984.

9. Okely $A D$, Ghersi D, Hesketh KD, Santos R, Loughran SP, Cliff DP, et al: A collaborative approach to adopting/adapting guidelines. The Australian 24-Hour Movement Guidelines for the Early Years (Birth to 5 years): An Integration of Physical Activity, Sedentary Behaviour, and Sleep. BMC Public Health. 2017:17(5) [in press]

10. Timmons BW, LeBlanc AG, Carson V, Connor Gorber S, Dillman C, Janssen I, et al. Systematic review of physical activity and health in the early years (aged 0-4 years). Appl Physiol, Nutr Metab. 2012;37(4):773-92.

11. LeBlanc AG, Spence JC, Carson V, Connor Gorber S, Dillman C, Janssen I, et al. Systematic review of sedentary behaviour and health indicators in the early years (aged 0-4 years). Appl Physiol Nutr Metab. 2012;37(4):753-72.

12. Chen $X$, Beydoun MA, Wang $Y$. Is sleep duration associated with childhood obesity? A systematic review and meta-analysis. Obesity. 2008;16(2):265-74.

13. Kuzik N, Poitras VJ, Tremblay MS, Lee E-Y, Hunter S, Carson V. Systematic review of the relationships between combinations of movement behaviours and health indicators in the early years (0-4 years). BMC Public Health. 2017;17:5. [in press]

14. Chaput JP, Gray CE, Poitras VJ, Carson V, Gruber R, Birken CS, et al. Systematic review of the relationships between sleep duration and health indicators in the early years (0-4 years). BMC Public Health. 2017:17:5. [in press]

15. Carson V, Lee EY, Hewitt L, Jennings C, Hunter S, Kuzik N, et al. Systematic review of the relationships between physical activity and health indicators in the early years (0-4 years). BMC Public Health. 2017;17(5) [in press].

16. Poitras VJ, Gray CE, Janssen X, Aubert S, Carson V, Faulkner G, et al. Systematic review of the relationships between sedentary behaviour and health indicators in the early years (0-4 years). BMC Public Health. 2017;17:5. [in press]

17. Santos R, Cliff DP, Howard SJ, Veldman SL, Wright IM, Sousa-Sa E, et al. "GET-UP" study rationale and protocol: a cluster randomised controlled trial to evaluate the effects of reduced sitting on toddlers' cognitive development. BMC Pediatr. 2016;16(1):182

18. Trost SG, Fees BS, Haar SJ, Murray AD, Crowe LK. Identification and validity of accelerometer cut-points for toddlers. Obesity (silver spring). MD. 2012;20(11):2317-9.

19. Van Cauwenberghe E, Gubbels J, De Bourdeaudhuij I, Cardon G. Feasibility and validity of accelerometer measurements to assess physical activity in toddlers. Int J Behav Nutr Phys Act. 2011;8:67.

20. Group WHOMGRS. WHO child growth standards based on length/height, weight and age. Acta Paediatr Suppl. 2006;450:76-85.

21. Pink B. Technical paper. Socio-economic indexes for areas (SEIFA). Australian Bureau of Statistics. Catalogue no. 2033.0.55.001. Canberra. 2011. ABoSCn. 2011 canberra, 2033.0.55.001.

22. Lee E-Y, Hesketh KD, Hunter S, Kuzik N, Rhodes RE, Rinaldi CM, et al. Meeting new Canadian 24-hour movement guidelines for the early years and associations with adiposity among toddlers living in Edmonton, Canada. BMC Public Health. 2017:17:5. [in press]

23. Chaput JP, Colley RC, Aubert S, Carson V, Janssen I, Roberts KC, Tremblay MS. Proportion of preschool-aged children meeting the Canadian 24-Hour Movement Guidelines and associations with adiposity: results from the Canadian Health Measures Survey. BMC Public Health. 2017;17(5) [in press]

24. Cliff DP, McNeill J, Vella SA, Howard S, Santos R, Batterham M, et al. Adherence to 24-Hour Movement Guidelines for the Early Years and associations with social-cognitive development among Australian preschool children. BMC Public Health. 2017;17(5) [in press]

25. Ferreira RW, Rombaldia AJ, Ricardob LIC, Hallal PC, Azevedo MR. Prevalence of sedentary behavior and its correlates among primary and secondary school students. Revista Paulista de Pediatria. 2016:34(1):56-63.

26. Downing KL, Hinkley T, Salmon J, Hnatiuk JA, Hesketh KD. Do the correlates of screen time and sedentary time differ in preschool children? BMC Public Health. 2017:17(1):285

27. Gomes TN, dos Santos FK, Santos D, Pereira S, Chaves R, Katzmarzyk PT, et al. Correlates of sedentary time in children: a multilevel modelling approach. BMC Public Health. 2014;14:890.

28. Stierlin AS, De Lepeleere S, Cardon G, Dargent-Molina P, Hoffmann B, Murphy $\mathrm{MH}$, et al. A systematic review of determinants of sedentary behaviour in youth: a DEDIPAC-study. Int J Behav Nutr Phys Act. 2015:12:133.

29. De Craemer M, De Decker E, De Bourdeaudhuij I, Vereecken C, Deforche B, Manios $Y$, et al. Correlates of energy balance-related behaviours in preschool children: a systematic review. Obes Rev. 2012;13(Suppl 1):13-28.

30. Hoyos Cillero I, Jago R. Systematic review of correlates of screen-viewing among young children. Prev Med. 2010;51(1):3-10.

31. Duch H, Fisher EM, Ensari I, Harrington A. Screen time use in children under 3 years old: a systematic review of correlates. Int J Behav Nutr Phys Act. 2013;10:102

32. Arundell L, Fletcher E, Salmon J, Veitch J, Hinkley T. The correlates of afterschool sedentary behavior among children aged 5-18 years: a systematic review. BMC Public Health. 2016:16:58.

33. Tonge $\mathrm{KL}$, Jones $\mathrm{RA}$, Okely $\mathrm{AD}$. Correlates of children's objectively measured physical activity and sedentary behavior in early childhood education and care services: a systematic review. Prev Med. 2016;89:129-39.

34. Jones RA, Hinkley $T$, Okely AD, Salmon J. Tracking physical activity and sedentary behavior in childhood: a systematic review. Am J Prev Med. 2013:44(6):651-8.

35. Biddle SJ, Pearson N, Ross GM, Braithwaite R. Tracking of sedentary behaviours of young people: a systematic review. Prev Med. 2010;51(5):345-51.

36. Janssen X, Mann KD, Basterfield L, Parkinson KN, Pearce MS, Reilly JK, et al. Development of sedentary behavior across childhood and adolescence: longitudinal analysis of the Gateshead millennium study. Int J Behav Nutr Phys Act. 2016;13:88

37. Saunders TJ, Gray CE, Poitras VJ, Chaput JP, Janssen I, Katzmarzyk PT, et al. Combinations of physical activity, sedentary behaviour and sleep: relationships with health indicators in school-aged children and youth. App Physiol Nutr Metab. 2016;41(6 Suppl 3):S283-93.

38. Carson V, Hunter S, Kuzik N, Gray CE, Poitras VJ, Chaput JP, et al. Systematic review of sedentary behaviour and health indicators in school-aged children and youth: an update. Appl Physiol Nutr Metab. 2016;41 (6 Suppl 3):S240-65.

39. Chaput JP, Gray CE, Poitras VJ, Carson V, Gruber R, Olds T, et al. Systematic review of the relationships between sleep duration and health indicators in school-aged children and youth. Appl Physiol Nutr Metab. 2016;41(6 Suppl 3):S266-82.

40. Poitras VJ, Gray CE, Borghese MM, Carson V, Chaput JP, Janssen I, et al. Systematic review of the relationships between objectively measured physical activity and health indicators in school-aged children and youth. Appl Physiol Nutr Metab. 2016;41(6 Suppl 3):S197-239.

41. Ekelund U, Luan J, Sherar LB, Esliger DW, Griew P, Cooper A. Moderate to vigorous physical activity and sedentary time and cardiometabolic risk factors in children and adolescents. JAMA. 2012;307(7):704-12. 